\title{
Pre-treatment loss to follow-up and treatment delay among bacteriologically- confirmed tuberculosis patients diagnosed in Mandalay Region, Myanmar
}

Ko Ko Htwe ${ }^{1^{*}}$ (D) Nang Thu Thu Kyaw², Ajay M. V. Kumar ${ }^{2}$, Khine Wut Yee Kyaw², Myo Minn Oo², Thandar Thwin', Saw Saw ${ }^{3}$ and Si Thu Aung ${ }^{4}$

\begin{abstract}
Background: Pre-treatment loss to follow-up (PTLFU) among tuberculosis (TB) patients is a global public health problem, because such patients are highly infectious and experience high mortality. There is no published evidence on this issue from Myanmar.

Objective: To determine PTLFU and treatment delays ( $>7$ days duration between the date of diagnosis and starting anti-TB treatment) and their associated demographic, clinical, and health system-related factors among bacteriologically confirmed (sputum smear-positive and/or Xpert-positive) TB patients diagnosed in public health facilities of the Mandalay Region between January and June 2017.

Method: This was a cohort study involving secondary analysis of routine programme data. Every bacteriologically confirmed TB patient in the laboratory register was tracked for at least 3 months in the treatment register. Patients neither found in the treatment register nor referred out for treatment were considered PTLFU.

Results: Of the 1365 bacteriologically confirmed patients diagnosed, 1051 (77\%) started on anti-TB treatment, 200 (15.6\%) were referred for treatment to health facilities outside the study area, and 114 (8.4\%, 95\% Cl 7.0\%-9.9\%) did not initiate anti-TB treatment (PTLFU). PTLFU was significantly higher in those with TB/HIV co-infected (18\%), sputum smear-negative but Xpert MTB-positive patients (31\%), and patients diagnosed at a moderate- or high-volume facility (> 50 patients tested form TB during the study period) ( 10\%). Of the 940 patients with dates recorded, 46 (5\%) had a treatment delay of more than 7 days. Patients aged 45-64 years had higher risk of treatment delay compared to those aged 15-44 years. About $97 \%$ of records did not have a phone number recorded.

Conclusion: PTLFU and treatment delay were relatively low in the Mandalay Region. While this is reassuring, urgent steps must be taken to address those that are lost, which includes improving documentation of phone numbers to improve 'trackability', instituting proactive measures to trace patients lost in the care pathway, and introducing an indicator in the national tuberculosis programme (NTP) monthly report to monitor and review PTLFU. Patient subgroups with higher PTLFU should receive priority attention.
\end{abstract}

Keywords: Tuberculosis, Myanmar, SORT IT, Operational research, Laboratory register, Recording

\footnotetext{
* Correspondence: kokohtwe81@gmail.com

${ }^{1}$ National TB Programme, Central-Mandalay Branch, Department of Public

Health, Ministry of Health and Sports, Patheingyi Township, Mandalay

Region, Myanmar

Full list of author information is available at the end of the article
}

C The Author(s). 2019 Open Access This article is distributed under the terms of the Creative Commons Attribution 4.0 International License (http://creativecommons.org/licenses/by/4.0/), which permits unrestricted use, distribution, and

reproduction in any medium, provided you give appropriate credit to the original author(s) and the source, provide a link to the Creative Commons license, and indicate if changes were made. The Creative Commons Public Domain Dedication waiver (http://creativecommons.org/publicdomain/zero/1.0/) applies to the data made available in this article, unless otherwise stated. 


\section{Background}

Myanmar is one of the 30 high tuberculosis (TB) burden countries ranking 11th globally and 4th in the Southeast Asia region after India, Bangladesh, and Indonesia. In 2016, an estimated 191,000 people developed TB and 30,000 of them died in Myanmar [1].

Early detection and rapid initiation of treatment of all TB patients are necessary to reduce mortality, morbidity, and disease transmission in the community as well as in health care settings (nosocomial transmission). In 2016, the TB case detection rate in Myanmar was $72 \%$ [2]. This implies that $28 \%$ of TB patients were either not diagnosed and treated or not notified to the national TB programme. Identifying these 'missing' patients and linking them to appropriate care is important for Myanmar to end TB as envisaged by the END-TB strategy of the World Health Organization and United Nations' Sustainable Development Goals [3, 4].

One of the possible reasons for 'missing' patients is pre-treatment loss to follow-up (PTLFU), which is defined as the proportion of diagnosed TB patients not registered on treatment. Studies on the TB care cascade show that PTLFU exceeds the combined rates of loss to follow-up (LFU), death, and failure after initiation of treatment [5]. Several studies conducted across the globe have shown that the PTLFU among TB patients varies from 4 to $38 \%, 18 \%$ (95\% confidence intervals (CI) 13-22) in Africa and 13\% (95\% CI 10-15) in Asia [6]. Such patients, when untreated, are likely to transmit the disease to others and eventually die due to the disease [7-9]. Unfortunately, national TB programmes (NTPs) in most countries do not routinely report PTLFU and monitor this indicator.

The other related issue is the delay in initiating TB treatment (defined as $>7$ days duration between the date of diagnosis and starting anti-TB treatment), as reported by many studies from high TB burden countries [10-15].

However, in Myanmar, there is no published evidence on the magnitude of PTLFU and the delays in treatment initiation among TB patients. In this study, we aimed to determine PTLFU and delays in starting treatment and their associated demographic, clinical, and health-system related factors among bacteriologically confirmed TB patients (sputum smear-positive and/or Xpert MTB-positive) diagnosed in public health facilities in Mandalay region between January and June 2017. We excluded patients diagnosed in private clinics and hospitals in this study due to the lack of systematic recording and reporting to NTP.

\section{Methods}

Design

This was a cohort study.

\section{Study setting}

Mandalay is one of the 15 regions/states of Myanmar with a population of 5.1 million [16]. Mandalay is located in central Myanmar and administratively divided into 28 townships.

The NTP carries the overall responsibility for TB control in the Mandalay Region. TB control activities are implemented at township level as part of integrated primary health care provision by township TB teams located at township public health centres, consisting of medical officer, laboratory technician, staff nurse, and junior TB worker, under the guidance, supervision, and monitoring of the district, state/region, and central units of NTP. The basic health staffs are trained for TB control at the grass root level. While most TB patients are managed in the public sector under NTP, a small proportion is diagnosed and treated in private clinics and hospitals, especially in urban areas, which are not under the supervision of NTP in this setting.

\section{Diagnosis of TB}

The process of diagnosis and linkage to care for bacteriologically confirmed tuberculosis patients in Myanmar is shown in Fig. 1. Presumptive TB patients, defined as those with cough $>2$ weeks, fever, night sweats, weight loss, or enlarged lymph nodes, identified at the health facilities or in community-based active case finding projects are referred to the nearest township TB laboratory. In some instances, sputum specimens of presumptive TB patients are collected and transported to the laboratory. The diagnosis of TB is primarily based on direct sputum smear microscopy. Two sputum samples (one spot and one early morning specimen) are examined to diagnose pulmonary TB by using light microscopy with Ziehl-Neelsen stain or florescence microscopy using auramine stain.

Xpert $^{\oplus}$ MTB/RIF assay (Xpert test) is used primarily for the diagnosis of rifampicin resistance, except among people living with HIV (PLHIV) where it is used for the diagnosis of $\mathrm{TB}$ along with sputum microscopy. So, all presumptive TB patients, except PLHIV, are first tested using sputum microscopy and, if found smear-positive for acid-fast bacilli, are started on the first-line TB treatment and further tested for rifampicin resistance by Xpert test as per NTP guidelines. If the Xpert test is available in the same health facility, an additional specimen is collected and tested. In health facilities without Xpert test, smear-positive TB patients are referred to the nearest laboratory for Xpert test. Sputum smear and Xpert test results are routinely recorded in the laboratory register. Based on the results of the Xpert test (rifampicin resistant or sensitive), patients are either continued on first-line treatment or changed to second-line treatment. Among presumptive TB patients with HIV, both sputum smear microscopy and Xpert 


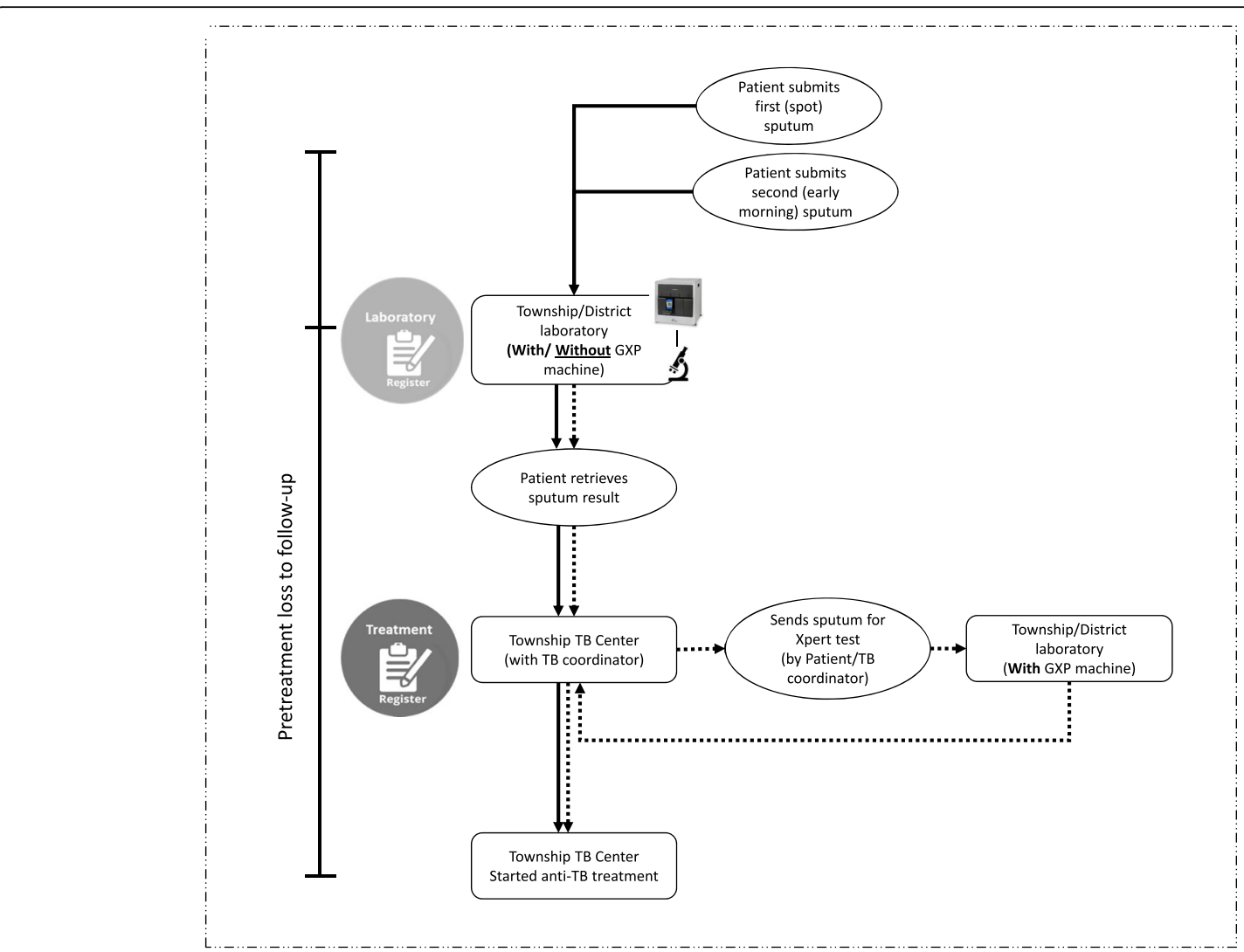

Fig. 1 The process of diagnosis and linkage to care for bacteriologically confirmed tuberculosis patients in Myanmar between January and June 2017. TB, tuberculosis; GXP, Gene Xpert machine; Xpert test, Xpert ${ }^{\circledR}$ MTB/RIF assay; solid line, the process if the sputum smear was tested at facility with GXP machine; dotted line, the process if the sputum smear was tested at facility without GXP machine

testing are done simultaneously, and based on the results, the appropriate treatment is initiated.

In the Mandalay Region, there are a total of 62 microscopy centres. Of these, eight laboratories also perform Xpert $^{\circ}$ MTB/RIF assay. In 2016, a total of 4186 bacteriologically confirmed patients were registered for treatment in the Mandalay Region [17].

\section{Treatment for TB}

TB patients are registered in the TB treatment register and started on treatment by the township TB coordinator at township TB centres. Patients diagnosed as out-patients in general, station, and TB hospitals are referred to the respective township TB centre for treatment initiation and registration. TB patients diagnosed among in-patients are treated while hospitalised and then referred to the respective township for the continuation of treatment. TB patients diagnosed from community-based active case finding activities are linked to treatment by the community volunteers. $\mathrm{TB}$ diagnosis and treatment is provided free of cost to all the patients.

\section{Study population}

All bacteriologically confirmed TB patients diagnosed at 21 township public health centres in the Mandalay Region of Myanmar between January and June 2017 were included. These 21 facilities were conveniently selected out of 28 township public health centres based on availability and access to programme data. We excluded private clinics and hospitals, clinics run by non-governmental organisations, and patients diagnosed with rifampicin resistance diagnosed by Xpert MTB/RIF test as these patients have different bacteriological and clinical profiles and have already been studied before [18].

\section{Data variables, sources, and management}

Data collection and entry was done between December 2017 and April 2018. To facilitate efficient tracking, we digitised the TB laboratory and treatment registers. Digitisation was done in a quality-assured (double entry validation) manner using EpiData software (v3.1, EpiData Association, Odense, Denmark) by trained data entry operators. 


\section{Digitisation of laboratory register}

The study cohort was constituted by digitising the TB laboratory registers for the period January-June 2017. The variables included name, age, sex, HIV status, previous history of TB treatment, results of sputum microscopy and Xpert MTB/RIF, name of health facility, phone number (recorded or not), date of diagnosis, and referral for treatment. It is expected that the patients are tested at multiple laboratories especially in situations where Xpert test services are not available in the same health facility. We, therefore, searched the laboratory database for duplicate patient entries and removed them.

\section{Digitisation of treatment register}

We then digitised the TB treatment registers for the period January-September 2017. This enabled the tracking of every diagnosed TB patient for at least 3 months, until September 30, 2017. Variables extracted from the TB register include name, age, sex, name of health facility, laboratory serial number, HIV status, and date of treatment initiation. If there was a discrepancy in variables between laboratory and treatment registers, laboratory register was considered final for all variables except HIV status. For HIV status, the information from TB register was used to update the information in the laboratory register.

\section{Matching of laboratory and treatment registers}

For each patient listed in the laboratory database, we searched the treatment database to assess for PTLFU. We used the VLOOKUP function in MS Excel to match the laboratory and treatment databases using the following variables: laboratory serial number, patient name, age, sex, and township. The laboratory number and patient name were the primary tracking variables, while the other variables were used for confirmation. For records where we did not find an exact match (due to variations in the spellings of patient name), we looked at the other variables and decided this was a 'match' only if we had a perfect match for sex and township and an approximate match for age ( \pm 2 years).

\section{Operational definitions}

Bacteriologically confirmed TB patients: Patients whose sputum smear and/or Xpert MTB results were positive in the laboratory register.

Started on anti-TB treatment: Patients found in the treatment database as per the above-mentioned criteria were considered 'Started on anti-TB treatment'.

Referral for treatment: Patients who were documented in the laboratory register to have been referred out of the study area for treatment were considered 'Referral for treatment'.
PTLFU: Bacteriologically confirmed TB patients found in the laboratory database but were neither referred out nor found in the treatment database were considered PTLFU.

Treatment delay: If the duration between the date of diagnosis and treatment start was more than 7 days, it was considered 'treatment delay'.

Categories of health facilities: Based on the number of sputum-positive patients diagnosed in the study period, health facilities were classified into three categories: (i) high volume ( $>70$ patients), (ii) moderate volume (5070 patients), and (iii) low volume ( $<50$ patients). The cut-offs were chosen based on the median and 75 th percentile.

\section{Data analysis and statistics}

Data was analysed using EpiData (version 2.2.2.183) and Stata (version 12, Texas, USA) software. We used medians and interquartile ranges (IQR) or numbers and percentages to describe the patient characteristics. We assessed the associations of demographic and clinical factors with outcomes using relative risks (RR) and 95\% confidence intervals (CI). Factors with $p$ value $<0.2$ in unadjusted analysis and age and sex were included in a multivariable model (log-binomial regression or Poisson regression with robust error estimates if convergence was not obtained in the binomial model) to determine the independent factors associated with outcomes. Level of significance was set at $5 \%$. We adhered to the STROBE (Strengthening The Reporting of Observational studies in Epidemiology) guidelines for conduct and reporting of the study [19].

\section{Results}

There were 1365 bacteriologically confirmed TB patients in the study. Median age of participants was 40 years (IQR 30-52 years), 1018 (75\%) were male, 71 (5\%) were recorded as HIV-positive, 110 (8\%) had a previous history of anti-TB treatment, and 729 (53\%) were diagnosed from a 'high volume' facility (Table 1).

\section{PTLFU}

Of the TB patients diagnosed, 1051 (77\%) were started on anti-TB treatment, 200 (15.6\%) were referred for treatment to health facilities outside the study area, and 114 (8.4\%) did not initiate anti-TB treatment (Fig. 2). Thus, the proportion of PTLFU among the bacteriologically confirmed TB patients was $8.4 \%$ (95\% CI 7.0$9.9 \%)$. If patients referred for treatment were excluded from the denominator, then PTLFU was 9.8\% (95\% CI 8.2-11.6\%). The PTLFU was higher in some patient subgroups like HIV-positive patients (18.3\%), previously treated patients (20\%), and smear-negative but Xpert-positive patients (30.7\%). In addition, patients 
Table 1 Demographic and clinical profile of bacteriologicallyconfirmed TB patients diagnosed in 21 township health centres of Mandalay Region of Myanmar between January and June 2017

\begin{tabular}{|c|c|}
\hline Characteristics & Number (\%) \\
\hline Total & $1365(100)$ \\
\hline \multicolumn{2}{|l|}{ Age (years) } \\
\hline$<15$ & $8(0.6)$ \\
\hline $15-44$ & $805(59.9)$ \\
\hline $45-64$ & $425(31.1)$ \\
\hline$\geq 65$ & $127(9.3)$ \\
\hline \multicolumn{2}{|l|}{ Gender } \\
\hline Male & $1018(74.6)$ \\
\hline Female & $347(25.4)$ \\
\hline \multicolumn{2}{|c|}{ Phone number recorded or not } \\
\hline Yes & $38(2.8)$ \\
\hline No & $1327(97.2)$ \\
\hline \multicolumn{2}{|l|}{ HIV status } \\
\hline Positive & $71(5.2)$ \\
\hline Negative & $1060(77.7)$ \\
\hline Unknown & $234(17.1)$ \\
\hline \multicolumn{2}{|l|}{ History of TB treatment } \\
\hline Yes & $110(8.1)$ \\
\hline No & $864(63.3)$ \\
\hline Unknown & 391 (28.6) \\
\hline \multicolumn{2}{|l|}{ Sputum smear result } \\
\hline Positive & $1303(95.5)$ \\
\hline Negative & $62(4.5)$ \\
\hline \multicolumn{2}{|l|}{ Xpert MTB/RIF result } \\
\hline No MTB & $28(2.1)$ \\
\hline Invalid & $2(0.2)$ \\
\hline MTB detected & $636(46.6)$ \\
\hline Not recorded & $699(51.2)$ \\
\hline \multicolumn{2}{|l|}{ Site of sputum microscopy } \\
\hline Low-volume facility & $308(22.6)$ \\
\hline Moderate-volume facility & $328(24)$ \\
\hline High-volume facility & $729(53.4)$ \\
\hline
\end{tabular}

TB tuberculosis, MTB mycobacterium tuberculosis, RIF rifampicin

diagnosed at a moderate or high-volume facility were significantly associated with higher risk of PTLFU (Table 2).

\section{Treatment delay}

Of the 940 patients with valid dates of diagnosis and treatment start, $46(5 \%)$ had a treatment delay of more than 7 days. The median duration between diagnosis and treatment start was 1 day (IQR $0-2$ days). Patients aged 45-64 years had a higher risk of treatment delay compared to those aged $15-44$ years (Table 3 ).

\section{Completeness of records in laboratory register}

Of the 1365 records evaluated, 1327 (97\%) records did not have phone number recorded, 666 (49\%) records did not have HIV testing information, and 699 (51\%) did not have Xpert MTB/RIF test results. Of the 1327 patients who did not have a phone number in laboratory register, $926(70 \%)$ had a phone number recorded in the treatment register. Of the 699 patients lacking Xpert results in the laboratory register, 301 (43\%) had Xpert results in the treatment register.

\section{Discussion}

This is the first study from Myanmar reporting PTLFU and treatment delay among bacteriologically confirmed patients without known rifampicin resistance. It was reassuring to find that PTLFU and treatment delays were relatively lower compared to average PTLFU rates and delays reported in African and Asian settings [6, 11, 20-22].

We believe PTLFU of $8 \%$ is an underestimate for the following reasons. First, we included patients 'referred for treatment' as part of the denominator. If they were excluded from the denominator, as has been the case in most of the previous studies, PTLFU increases marginally to $\sim 10 \%$. Programme experience indicates that most of the patients with documented referral start treatment. However, this needs to be formally studied.

Second, we had excluded many high-volume health facilities in the Mandalay Region from our study, due to operational difficulties of accessing data. These facilities attract patients from all over the region, and PTLFU is likely to be higher in patients diagnosed in such facilities, possibly due to long distances, patient mobility, and losses in the complicated referral process after diagnosis. While it is possible that some of the patients declared PTLFU in our study may have been started on treatment in the private health sector, we believe such instances are limited and may not have impacted our estimate of PTLFU greatly. This needs further study.

We identified several factors associated with PTLFU in our study. HIV-infected TB patients experienced a higher risk of PTLFU, probably due to higher case fatality in this group, which in turn may be due to late presentation to the health facility coupled with severe illness. This has been shown in several studies from Africa, the region most severely affected by the HIV-TB epidemic [23]. A previous qualitative study from South Africa reports stigma as one of the other reasons for PTLFU among HIV-TB patients [24].

Previously treated TB patients had a higher risk of PTLFU compared to new patients, as has been reported by a recent study in India [21]. This may again be due to severe illness at presentation and higher case fatality in this group. 


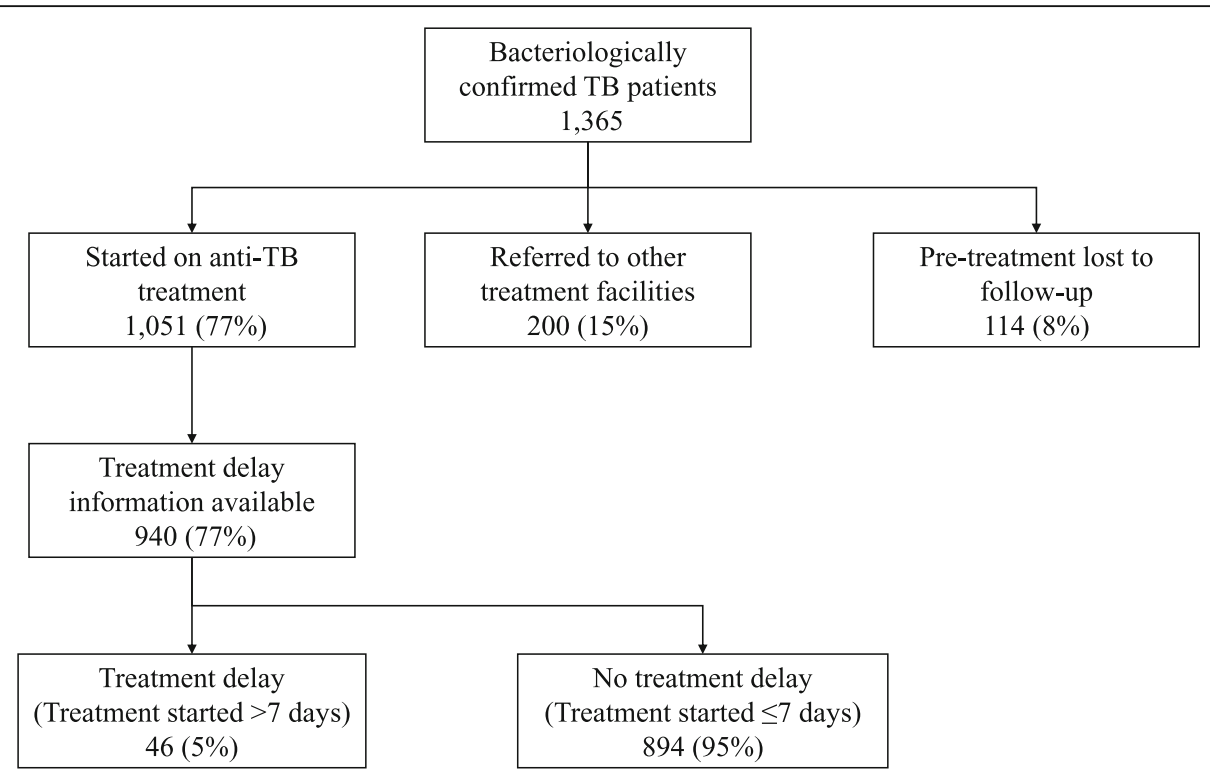

Fig. 2 Flow chart of bacteriologically confirmed TB patients diagnosed in 21 township health centres of Mandalay Region of Myanmar between January and June 2017. TB, tuberculosis

Patients who were sputum smear-negative but Xpert-positive had a higher risk of PTLFU. This is a novel risk factor identified, but not reported in previous studies. Although we do not know the exact reasons, we speculate that this may be related to the profile of patients and access to Xpert testing. In Myanmar, sputum smear-negative presumptive TB patients are offered Xpert testing only if they have accompanying HIV or diabetes mellitus or if they are a contact of multidrug-resistant $\mathrm{TB}$ patients or on request of the specialist physicians in selected, severely ill, sputum-negative patients with high index of suspicion of TB. This needs further exploration in future studies.

Another risk factor identified in our study was related to the volume of patients diagnosed in health facilities. Barring a recent study from India, no other study has examined this aspect [21]. Similar to the study from India, we also found that patients diagnosed in high-volume and moderate-volume facilities had a higher risk of PTLFU compared to low-volume health facilities [21]. We speculate that this may be due to two reasons: (i) patients diagnosed in low-volume facilities are more likely to be residing close to the facilities whereas high-volume facilities (generally referral facilities) are likely to attract patients from distant areas and (ii) patients in low-volume facilities may have had more favourable provider-patient interactions compared to high-volume facilities, where the staff are often overburdened and the time spent per patient is likely to be less.

The documentation of phone numbers was poor in the laboratory register, similar to other settings [25]. This is an index of 'trackability' of TB patients, and previous studies have shown that this is an important factor associated with PTLFU [21]. We believe most of the TB patients in Myanmar have access to mobile phones, and documenting it in the laboratory register will help in actively tracking 'lost' patients.

Only 1 in 20 patients had a treatment delay of more than 7 days in our study, as compared to $42 \%$ of patients experiencing a delay in a study from India [11]. The median delay in our study was just 1 day, compared to 2 days in a study from Ethiopia [26]. We found TB patients aged 45 years and above had a higher risk of delay. So, older patients should be a focus of our interventions aiming to reduce the delays. There may be other factors associated with treatment delay which we did not collect data on. Delay has been associated with both patient-related factors (male, low income, severity of disease, unemployment, poor knowledge of TB) and health system-related factors (lack of qualified providers, long travel times and distances to a health facility) [10-15].

There were a couple of methodological strengths in our study. First, we employed a systematic method to digitise the laboratory and treatment registers and matched the two databases using a combination of electronic tracking, backed up by manual checking for every patient. This minimised the misclassification of PTLFU. Second, we performed a cohort analysis, thus providing a more accurate estimate of PTLFU, compared to that obtained by comparison of aggregate data routinely reported by NTP.

The study also had some limitations. As discussed above, we may have underestimated the magnitude of PTLFU. Also, we need to exercise caution before generalising the results to other regions of the country. Given 
Table 2 Factors associated with pre-treatment loss to follow-up among bacteriologically confirmed TB patients diagnosed in 21 township health centres of the Mandalay Region of Myanmar between January and June 2017

\begin{tabular}{|c|c|c|c|c|}
\hline Characteristics & Total $(n)$ & PTLFU $(n(\%))$ & RR $(95 \% \mathrm{Cl})$ & aRR $(95 \% \mathrm{Cl})$ \\
\hline Total & 1365 & $114(8.4)$ & & \\
\hline \multicolumn{5}{|l|}{ Age (years) } \\
\hline$<15$ & 8 & $2(25.0)$ & $3.0(0.9-10.2)$ & $1.3(0.3-5.4)$ \\
\hline $15-44$ & 805 & $67(8.3)$ & Ref & Ref \\
\hline $45-64$ & 425 & $38(8.9)$ & $1.1(0.7-1.6)$ & $0.9(0.6-1.4)$ \\
\hline$\geq 65$ & 127 & $7(5.5)$ & $0.7(0.3-1.4)$ & $0.6(0.2-1.3)$ \\
\hline \multicolumn{5}{|l|}{ Gender } \\
\hline Male & 1018 & $86(8.5)$ & Ref & Ref \\
\hline Female & 347 & $28(8.1)$ & $0.9(0.6-1.4)$ & $1.0(0.65-1.55)$ \\
\hline \multicolumn{5}{|l|}{ Phone number } \\
\hline Recorded & 38 & $1(2.6)$ & $0.3(0.0-2.2)$ & \\
\hline Not recorded & 1327 & $113(8.5)$ & Ref & \\
\hline \multicolumn{5}{|l|}{ HIV status } \\
\hline Positive & 71 & $13(18.3)$ & $3.5(2.0-6.1)$ & $2.7(1.4-5.0)$ \\
\hline Negative & 1060 & $55(5.2)$ & Ref & Ref \\
\hline Unknown & 234 & $46(19.7)$ & $3.8(2.6-5.5)$ & $4.2(2.7-6.4)$ \\
\hline \multicolumn{5}{|l|}{ History of TB treatment } \\
\hline Yes & 110 & $22(20.0)$ & $2.5(1.6-3.9)$ & $1.7(0.9-2.8)$ \\
\hline No & 864 & $68(7.9)$ & Ref & Ref \\
\hline Unknown & 391 & $24(6.1)$ & $0.8(0.5-1.2)$ & $0.5(0.3-0.8)$ \\
\hline \multicolumn{5}{|l|}{ Sputum result } \\
\hline Smear positive & 1303 & $95(7.3)$ & Ref & Ref \\
\hline Smear negative Xpert positive & 62 & $19(30.7)$ & $4.2(2.8-6.4)$ & $2.6(1.4-4.6)$ \\
\hline \multicolumn{5}{|l|}{ Site of sputum microscopy } \\
\hline Low volume & 308 & $11(3.6)$ & Ref & Ref \\
\hline Moderate volume & 328 & $27(8.2)$ & $2.3(1.2-4.6)$ & $2.2(1.1-4.4)$ \\
\hline High volume & 729 & $76(10.4)$ & $2.9(1.6-5.4)$ & $1.7(0.9-3.2)$ \\
\hline
\end{tabular}

PTLFU pre-treatment loss to follow-up, TB tuberculosis, RR relative risk, aRR adjusted relative risk (adjusted for age, gender, HIV status, history of TB treatment, sputum result, site of sputum microscopy), Ref reference group. Text in boldface indicates the statistical significance at $p$ value $<0.001$

the differences in geography, ethnicity, and access to health care in different regions of Myanmar, we feel PTLFU and delays may differ. Similar research studies should be conducted in other regions and states for obtaining a national picture. Third, we did not know what happened to patients who were PTLFU. We did not actively track the 'lost' patients. Such efforts would have provided insights into the reasons for PTLFU and the potential yield of an active patient tracking system. Future operational research should focus on this issue using a combination of quantitative and qualitative research methods. Finally, there were missing data with reference to some key variables which might have affected the internal validity of our analysis.

There are several programme implications from this study. First, urgent measures are required to track patients not initiated on treatment. Such patients not only have high mortality and morbidity, but are also the source of continued disease transmission in the community and hospitals. Previous studies have shown that having a dedicated team to track patients is helpful in reducing the magnitude of PTLFU $[6,16]$. In the absence of such a team, the laboratory technician and the TB coordinator should meet periodically and exchange information. The patient's phone number and addresses should be properly documented in the laboratory register and used to improve the tracking of patients.

Second, NTP should introduce an indicator in the monthly or quarterly report to monitor PTLFU, which has suffered the neglect of programmes and policymakers globally, since it was first described five decades ago [27]. As the adage goes, "What gets monitored, gets done'. So, introducing the monitoring indicator and reviewing it periodically will sensitise the programme staff 
Table 3 Factors associated with treatment delay among bacteriologically confirmed TB patients who received treatment in 21 township health centres of the Mandalay Region of Myanmar between January and June 2017

\begin{tabular}{|c|c|c|c|c|}
\hline Variables & Total $(n)$ & Treatment delay $(n(\%))$ & RR $(95 \% \mathrm{Cl})$ & aRR $(95 \% \mathrm{Cl})$ \\
\hline Total & 940 & $46(4.9)$ & & \\
\hline \multicolumn{5}{|l|}{ Age (years) } \\
\hline$<15$ & 3 & $0(0.0)$ & & \\
\hline $15-44$ & 536 & $18(3.4)$ & Ref & Ref \\
\hline $45-64$ & 308 & $21(6.8)$ & $2.0(1.1-3.8)$ & $1.9(1.0-3.6)$ \\
\hline$\geq 65$ & 93 & $7(7.5)$ & $2.2(0.9-5.2)$ & $2.0(0.8-4.9)$ \\
\hline \multicolumn{5}{|l|}{ Gender } \\
\hline Male & 701 & $36(5.1)$ & Ref & Ref \\
\hline Female & 239 & $10(4.2)$ & $0.8(0.4-1.6)$ & $0.8(0.4-1.8)$ \\
\hline \multicolumn{5}{|l|}{ Phone number } \\
\hline Recorded & 31 & $2(6.5)$ & $0.3(0.0-2.2)$ & \\
\hline Not recorded & 909 & $44(4.8)$ & Ref & \\
\hline \multicolumn{5}{|l|}{ HIV status } \\
\hline Positive & 46 & $4(8.7)$ & $2.03(0.7-5.5)$ & $1.86(0.6-5.4)$ \\
\hline Negative & 864 & $37(4.3)$ & Ref & Ref \\
\hline Unknown & 30 & $5(16.7)$ & $3.89(1.6-9.2)$ & $3.76(1.4-9.9)$ \\
\hline \multicolumn{5}{|l|}{ History of TB treatment } \\
\hline Yes & 67 & $6(8.9)$ & $2.08(0.9-4.9)$ & $1.89(0.7-4.8)$ \\
\hline No & 630 & $27(4.3)$ & Ref & Ref \\
\hline Unknown & 243 & $13(5.4)$ & $1.24(0.6-2.4)$ & $1.15(0.6-2.3)$ \\
\hline \multicolumn{5}{|l|}{ Sputum result } \\
\hline Smear positive & 913 & $43(4.7)$ & Ref & Ref \\
\hline Smear negative Xpert positive & 27 & $3(11.1)$ & $2.35(0.8-7.1)$ & $1.46(0.4-5.1)$ \\
\hline Not recorded & 135 & $12(8.9)$ & $0.73(0.4-1.4)$ & \\
\hline \multicolumn{5}{|l|}{ Site of sputum microscopy } \\
\hline Low volume & 264 & $10(3.8)$ & Ref & Ref \\
\hline Moderate volume & 261 & $13(4.9)$ & $1.3(0.6-2.9)$ & $1.5(0.6-3.4)$ \\
\hline High volume & 415 & $23(5.5)$ & $1.5(0.7-3.0)$ & $1.6(0.7-3.4)$ \\
\hline
\end{tabular}

$T B$ tuberculosis, $R R$ relative risk, $a R R$ adjusted relative risk (adjusted for age, gender, HIV status, history of TB treatment, sputum result, site of sputum microscopy), Ref reference group. Text in boldface indicates the statistical significance at $p$ value $<0.001$

to pay attention to this neglected issue. The information on TB treatment initiation along with TB number should be recorded in the laboratory register, as recommended by the NTP in Myanmar. This enables easy cohort analysis compared to the complicated matching of records undertaken in this study (based on name, age, and other variables which are not often accurately documented). We also recommend documenting a government-issued unique identifier in both laboratory and treatment registers which helps in efficient tracking.

Third, to be able to track the whole cascade of TB diagnosis and treatment, the use of presumptive TB registers or cough registers at the township health centres should be strengthened. Using comprehensive electronic recording systems may be another option to improve the recording and tracking of patients, but this may require a significant investment of resources [25].

Fourth, patient cohorts for assessing treatment outcomes should be constituted from 'laboratory registers (all diagnosed patients)' and not 'treatment registers (all treated patients)' so that PTLFU is accounted for when assessing patient outcomes [28]. There are two consequences of doing this: an increase in case detection rates and a decrease in treatment success rates. If we extrapolate using the PTLFU rates found in our study to Myanmar, the treatment success rate may decrease from 87 to $80 \%$. But this step transparently and truthfully acknowledges the problem, which is often the first step in addressing it.

Finally, by not accounting for PTLFU in treatment outcomes, NTPs across the globe are deceiving themselves by 
reporting inflated treatment success rates. We recommend the World Health Organization to introduce a dedicated indicator in the global TB report and mandate this information from all countries. This is also essential to measure the third ' 90 ' (successfully treating 90\% of all 'diagnosed' TB patients) of the 90-90-90 targets set by the Stop TB Partnership to measure the progress of countries towards ending TB [29].

\section{Conclusion}

In conclusion, we found a relatively low level of PTLFU and treatment delay among TB patients in the Mandalay Region of Myanmar. While this is reassuring, urgent steps must be taken to address it which includes improving the documentation of phone numbers to improve 'trackability', instituting proactive measures to trace patients lost in the care pathway, and introducing an indicator in the NTP monthly report to monitor and review PTLFU. Patient subgroups with higher PTLFU should receive priority attention.

\section{Abbreviations}

$\mathrm{Cl}$ : Confidence intervals; HIV: Human immunodeficiency virus;

IQR: Interquartile range; LFU: Loss to follow-up; NTP: National TB programme; PLHIV: People living with HIV; PTLFU: Pre-treatment loss to follow-up; RR: Relative risks; STROBE: Strengthening The Reporting of Observational studies in Epidemiology; TB: Tuberculosis

\section{Acknowledgements}

This research was conducted through the Structured Operational Research and Training Initiative (SORT IT), a global partnership led by the Special Programme for Research and Training in Tropical Diseases at the World Health Organization (WHO/TDR). The model is based on a course developed jointly by the International Union Against Tuberculosis and Lung Disease (The Union) and Medécins sans Frontières (MSF/Doctors Without Borders). The specific SORT IT programme which resulted in this publication was jointly organised and implemented by the Centre for Operational Research, the Union, Paris, France; the Department of Medical Research, Ministry of Health and Sports, Myanmar; the Department of Public Health, Ministry of Health and Sports, Myanmar; the Union Country Office, Mandalay, Myanmar; the Union South-East Asia Office, New Delhi, India; and Burnet Institute, Australia.

\section{Funding}

The training programme, within which this paper was developed, was funded by the Department for International Development (DFID), UK, and the United States Agency for International Development (USAID) through Challenge TB and FHI 360. The funders had no role in the study design, data collection and analysis, decision to publish, or preparation of the manuscript.

\section{Availability of data and materials}

The datasets used and/or analysed during the current study are available from the corresponding author on reasonable request.

\section{Authors' contributions \\ $\mathrm{KKH}, \mathrm{NTTK}, \mathrm{AK}, \mathrm{SS}, \mathrm{MMO}, \mathrm{KWYK}, \mathrm{TT}$, and STA contributed to the conception and design of the study. $\mathrm{KKH}, \mathrm{MMO}$, and $\mathrm{KWYK}$ contributed to the data collection. KKH, NTTK, and AK contributed to the data analysis. KKH, NTTK, $\mathrm{AK}, \mathrm{SS}, \mathrm{MMO}, \mathrm{KWYK}, \mathrm{TT}$, and STA contributed to the data interpretation. $\mathrm{KKH}$, NTTK, and AK drafted the manuscript. KKH, NTTK, AK, SS, MMO, KWYK, TT, and STA contributed to the critical review and final approval.}

\section{Ethics approval and consent to participate}

The study was approved by the Ethical Review Committee of the Department of Medical Research, Myanmar, and the Union Ethics Advisory Group, Paris, France. The ethics committees waived the need for individual consent given the study involved only review of records with no direct interaction with patients.

\section{Consent for publication}

Not applicable.

\section{Competing interests}

The authors declare that they have no competing interests.

\section{Publisher's Note}

Springer Nature remains neutral with regard to jurisdictional claims in published maps and institutional affiliations.

\section{Author details}

${ }^{1}$ National TB Programme, Central-Mandalay Branch, Department of Public Health, Ministry of Health and Sports, Patheingyi Township, Mandalay Region, Myanmar. ${ }^{2}$ International Union Against Tuberculosis and Lung Disease, Mandalay, Myanmar. ${ }^{3}$ Department of Medical Research, Yangon, Myanmar. ${ }^{4}$ National TB Programme, Department of Public Health, Ministry of Health and Sports, Nay Pyi Taw, Myanmar.

Received: 25 November 2018 Accepted: 4 April 2019

Published online: 02 May 2019

\section{References}

1. World Health Organization. Global tuberculosis report 2017. Geneva: World Health Organization; 2017. http://apps.who.int/iris/bitstream/10665/259366/ 1/9789241565516-eng.pdf?ua=1.

2. World Health Organization. Global tuberculosis report 2016. Geneva: World Health Organization; 2016. http://apps.who.int/iris/bitstream/10665/250441/ 1/9789241565394-eng.pdf?ua=1\&ua=1. Accessed 19 Dec 2016.

3. United Nations. Transforming our world: the 2030 agenda for sustainable development. sustainable development knowledge platform. https:// sustainabledevelopment.un.org/post2015/transformingourworld. Accessed 16 May 2018.

4. Uplekar M, Weil D, Lonnroth K, Jaramillo E, Lienhardt C, Dias HM, et al. WHO's new End TB strategy. Lancet. 2015:385:1799-801.

5. Subbaraman R, Nathavitharana RR, Satyanarayana S, Pai M, Thomas BE, Chadha VK, et al. The tuberculosis cascade of care in India's public sector: a systematic review and meta-analysis. PLoS Med. 2016;13:e1002149.

6. MacPherson P, Houben RM, Glynn JR, Corbett EL, Kranzer K. Pre-treatment loss to follow-up in tuberculosis patients in low- and lower-middle-income countries and high-burden countries: a systematic review and meta-analysis. Bull World Health Organ. 2014;92:126-38.

7. Chiang C-Y, Lee J-J, Yu M-C, Bai K-J, Lin T-P, Luh K-T. Tuberculosis-related deaths without treatment. Int J Tuberc Lung Dis Off J Int Union Tuberc Lung Dis. 2009;13:1563-5.

8. Tostmann A, Kik SV, Kalisvaart NA, Sebek MM, Verver S, Boeree MJ, et al. Tuberculosis transmission by patients with smear-negative pulmonary tuberculosis in a large cohort in the Netherlands. Clin Infect Dis Off Publ Infect Dis Soc Am. 2008;47:1135-42.

9. Hernández-Garduño E, Cook V, Kunimoto D, Elwood RK, Black WA, FitzGerald JM. Transmission of tuberculosis from smear negative patients: a molecular epidemiology study. Thorax. 2004;59:286-90.

10. Bogale S, Diro E, Shiferaw AM, Yenit MK. Factors associated with the length of delay with tuberculosis diagnosis and treatment among adult tuberculosis patients attending at public health facilities in Gondar town, Northwest, Ethiopia. BMC Infect Dis. 2017;17:1-10.

11. Kant S, Singh A, Parmeshwaran G, Haldar P, Malhotra S, Kaur R. Delay in initiation of treatment after diagnosis of pulmonary tuberculosis in primary health care setting: eight year cohort analysis from district Faridabad, Haryana, North India. Rural Remote Health. 2017;17:4158-2017.

12. Li Y, Ehiri J, Tang S, Li D, Bian Y, Lin H, et al. Factors associated with patient, and diagnostic delays in Chinese TB patients: a systematic review and metaanalysis. BMC Med. 2013;11:156.

13. Cai J, Wang X, Ma A, Wang Q, Han X, Li Y. Factors associated with patient and provider delays for tuberculosis diagnosis and treatment in Asia: a systematic review and meta-analysis. PLOS ONE. 2015;10:e0120088.

14. Makwakwa L, Sheu M, Chiang C-Y, Lin S-L, Chang PW. Patient and heath system delays in the diagnosis and treatment of new and retreatment pulmonary tuberculosis cases in Malawi. BMC Infect Dis. 2014;14:132. 
15. Charles N, Thomas B, Watson B, Raja S, Chandrasekeran V, Nair SA, et al. Care seeking behavior of chest symptomatics: a community based study done in South India after the implementation of the RNTCP. PLoS One 5. PLOS ONE. 2010;7:e39040.

16. Department of Population, Ministry of Immigration and Population. The 2014 Myanmar population and housing census The Union Report. http:// myanmar.unfpa.org/en/node/15104. Accessed 1 Jan 2018.

17. National Tuberculosis Programme. National tuberculosis programme Myanmar annual report 2015. Ministry of Health and Sports Myanmar. https:/www.aidsdatahub.org/annual-report-2015-national-tuberculosisprogramme-myanmar-2017.

18. Htet KKK, Soe KT, Kumar AMV, Saw S, Win Maung HM, Myint Z, et al. Rifampicin-resistant tuberculosis patients in Myanmar in 2016: how many are lost on the path to treatment? Int J Tuberc Lung Dis Off J Int Union Tuberc Lung Dis. 2018:22:385-92.

19. von Elm E, Altman DG, Egger M, Pocock SJ, Gøtzsche PC, Vandenbroucke JP, et al. The Strengthening the Reporting of Observational Studies in Epidemiology (STROBE) statement: guidelines for reporting observational studies. Lancet Lond Engl. 2007;370:1453-7.

20. Ali SM, Naureen F, Noor A, Fatima I, Viney K, Ishaq M, et al. Loss-to-followup and delay to treatment initiation in Pakistan's national tuberculosis control programme. BMC Public Health. 2018;18:335.

21. Thomas BE, Subbaraman R, Sellappan S, Suresh C, Lavanya J, Lincy S, et al. Pretreatment loss to follow-up of tuberculosis patients in Chennai, India: a cohort study with implications for health systems strengthening. BMC Infect Dis. 2018;18:142

22. Mistry N, Rangan S, Dholakia Y, Lobo E, Shah S, Patil A. Durations and delays in care seeking, diagnosis and treatment initiation in uncomplicated pulmonary tuberculosis patients in Mumbai, India. PLoS ONE. 2016;11. https://doi.org/10.1371/journal.pone.0152287.

23. Storla DG, Yimer S, Bjune GA. A systematic review of delay in the diagnosis and treatment of tuberculosis. BMC Public Health. 2008;8:15.

24. Skinner D, Claassens M. It's complicated: why do tuberculosis patients not initiate or stay adherent to treatment? A qualitative study from South Africa. BMC Infect Dis. 2016;16:712.

25. Dunbar R, Lawrence K, Verver S, Enarson DA, Lombard C, Hargrove J, et al. Accuracy and completeness of recording of confirmed tuberculosis in two South African communities. Int J Tuberc Lung Dis. 2011;15:337-43.

26. Yimer S, Bjune G, Alene G. Diagnostic and treatment delay among pulmonary tuberculosis patients in Ethiopia: a cross sectional study. BMC Infect Dis. 2005;5:112.

27. M.A. Piot. A simulation model of case finding and treatment in tuberculosis control programmes. http://apps.who.int/iris/handle/10665/69827. Accessed 16 May 2018.

28. Harries AD, Rusen ID, Chiang C-Y, Hinderaker SG, Enarson DA. Registering initial defaulters and reporting on their treatment outcomes. Int J Tuberc Lung Dis. 2009;13:801-3.

29. Stop TB Partnership. The Global Plan to End TB / The Global Plan to Stop TB 2016 - 2020. http://www.stoptb.org/global/plan/plan2/. Accessed 17 May 2018

Ready to submit your research? Choose BMC and benefit from:

- fast, convenient online submission

- thorough peer review by experienced researchers in your field

- rapid publication on acceptance

- support for research data, including large and complex data types

- gold Open Access which fosters wider collaboration and increased citations

- maximum visibility for your research: over $100 \mathrm{M}$ website views per year

At BMC, research is always in progress.

Learn more biomedcentral.com/submissions 